\title{
Magra de ruim: gênero, sexualidade e a ficcionalização de si
}

\author{
Mariana Souza Paim*
}

\section{Introdução}

Ao menos há 100 anos as mulheres vêm se inserindo na cena de quadrinhos brasileira, ${ }^{1}$ mas nessa história parecem haver várias descontinuidades com relação ao acesso, inserção e a visibilidade alcançada pela produção das mulheres nesse meio, algo que se reflete no número de publicações que chegam ao público via grandes editoras, bem como se relaciona diretamente a questão do reconhecimento e as premiações ${ }^{2}$ dessas obras. Sendo esta uma ausência que se faz sentir também em meio as pesquisas científicas acerca dessa produção. O que pode ser entendido enquanto reflexo de um imaginário que associa tanto a produção quanto o consumo dos quadrinhos a dimensão masculina e as pensa como uma produção cultural menor.

Entretanto, nos últimos anos podemos constatar uma crescente movimentação tanto com relação a inserção das mulheres nas artes visuais, e mais especificamente nas narrativas gráficas, ${ }^{3}$ como da crítica. No contexto brasileiro, essa produção está em efervescência ao menos desde o ano de 2010, sendo que muito dessa movimentação tem se dado pela facilidade e contatos estabelecidos pela dissemi-

\footnotetext{
Doutoranda do programa de Literatura e Cultura da Universidade Federal da Bahia, também atua como professora da rede estadual de educação do Estado da Bahia, Brasil. E-mail: marianaspaim@gmail.com.

1 Muitas/os autoras/es apontam a produção de caricaturas de Nair de Teffé enquanto iniciativa pioneira na história dos quadrinhos no Brasil. Nascida no Rio de Janeiro no ano de 1886, a artista publicava suas charges em diversos jornais e revistas nacionais, como a Fon-Fon!, e internacionais sob o pseudônimo "Rian". Segundo a pesquisadora Natânia Nogueira, "Rian foi uma pioneira na caricatura no Brasil e há quem afirme que tenha sido a primeira mulher no mundo a publicar uma caricatura. Ela adentra a um espaço tipicamente masculino" (2011, p. 14).

2 Entre outros, lembramos aqui do Festival Internacional de Quadrinhos de Angoulême, considerado uma das mais importantes premiações ao lado do Eisner, que em 2015 entre os 30 indicados a principal categoria não contava com nenhuma mulher na lista e no qual, ao longo de $4^{2}$ edições, apenas uma mulher chegou a vencer o Grande Prêmio - a francesa Florence Cestac, em 200o. De forma semelhante no Brasil, o Troféu HQMix é um bom exemplo dessa exclusão. Em suas 27 edições, houve anos em que nenhuma mulher foi premiada (D’ANGELO, 2016).

3 Aqui utilizamos o termo narrativa gráfica enquanto uma "forma artística e literária que lida com a disposição de figuras ou imagens e palavras para narrar ou dramatizar uma ideia" (EISNER, 1989, p. 5), sendo as histórias em quadrinhos uma das suas expressões.
} 
nação e acesso às novas tecnologias de informação, mas principalmente pelo anseio de autorepresentação e autoexpressão em um meio quase que dominado exclusivamente por homens.

Existe atualmente uma enorme quantidade de grupos, fóruns, comunidades em diversas redes sociais e páginas próprias e/ou coletivas hospedadas em plataformas como o Tumblr, Instagram e Facebook, entre outras. Essas movimentações em meio virtual constantemente tem se desdobrado em ações e encontros presenciais, como as feiras e estandes de publicações, como o Vênus Press, cursos de formação e encontros, como o Lady's Comics ${ }^{4}$ e o [Des]enquadradas ${ }^{5}$ e as publicações coletivas, como a Zine XXX, publicada através de financiamento coletivo em 2014, em cinco volumes que reúnem as obras de diversas quadrinistas brasileiras. Sendo uma produção bastante heterogênea, com relação ao modo de produzir, técnicas e temas, as mulheres que fazem quadrinhos no país atualmente se autopublicam seja através da internet ou dos impressos de baixa tiragem e orçamento.

Grande parte dessas publicações são constituídas de fanzines, mas também têm sido mais constante as publicações impressas via crowdfunding, ou financiamento coletivo, e guardam consigo uma forte relação com os movimentos de mulheres da década de 1970, tanto com relação as questões políticas que são tematizadas em boa parte dessas produções, quanto com as publicações do período, como Wimmen's Comix, ${ }^{6}$ mas também com o movimento riot girrrl e a ideia do Do it Yourself! (Faça você mesm@!).7

Os fanzines surgem inicialmente nos Estados Unidos em 1930 como boletins de histórias de ficção científica criados fora do circuito editorial, mas ao longo do tempo tiveram seu sentido ampliado, podendo ser definido como:

Uma publicação independente e amadora, quase sempre de pequena tiragem, impressa em mimeógrafos, fotocopiadoras, ou pequenas impressoras offset. Para sua edição, contamos com fãs isolados, grupos e associações ou fã-clubes de determinada arte, personagem, personalidade, hobby

4 Lady's Comics é um coletivo que surgiu em 2010 como uma inciativa pautada na busca por pensar e refletir a produção de quadrinhos, especialmente das mulheres. O coletivo desenvolve diversas ações relacionadas a crítica e visibilidade da produção das mulheres nos quadrinhos, como a manutenção do site homônimo com resenhas, entrevistas e um banco de mulheres quadrinistas, o BAMQ!, a publicação da revista Risca! (2015), além de encontros e oficinas de formação para educadoras/es.

5 A primeira edição do evento ocorreu em Fortaleza no ano de 2014, tendo como proposta o debate sobre a relação entre consumo e produção dos quadrinhos feitos por mulheres.

6 Surgido na década de 1970 inicialmente com o nome It Aint Me Babe Comix, o Wimmen's Comics Collective era um coletivo formado exclusivamente por mulheres, voltado a publicação de quadrinhos feitos por mulheres, tendo como objetivo estabelecer um espaço de visibilidade e circulação dessa produção frente ao machismo e misoginia da cena underground do período.

7 É o nome de um movimento surgido nos Estados Unidos na década de 1990, envolvendo fanzines, música hardcore e punk rock feminista e festivais. O termo é uma referência a fanzine Riot Girrrl feita por Alison Wolfe, da Bratmobile, questionando o espaço das mulheres nas bandas de rock. 
ou gênero de expressão artística, para um público dirigido, podendo abordar um único tema ou uma mistura de vários (MAGALHÃEs, 2004, p. 27).

No Brasil esse tipo de publicação se tornou mais comum a partir da década de 1960, no contexto da ditadura e da censura aos meios de comunicação. Atualmente ganha novo fôlego, com outras roupagens e formatos, através das publicações dos coletivos compostos por mulheres quadrinistas como o Mandíbula, Zinas, Whatever 21, Foca no Rolê, Studio Seasons e Selo Pequi; e das autoras Beatriz Lopes, Gabi LoveLove6, Laura Athayde, Débora Santos, Dharilya Sales, Luiza de Souza, Renata Nolasco, Lila Cruz, Thays Koshino, Mariana Paraizo e Sirlanney Nogueira. Aqui buscaremos analisar as representações de gênero e sexualidade presentes na publicação Magra de ruim de autoria de Sirlanney Nogueira, editada em formato impresso em 2014.

\section{Magra de ruim}

Magra de ruim é uma das personagens criadas por Sirlanney Freire Nogueira, autora da publicação homônima que foi impressa pela primeira vez através de uma campanha de financiamento coletivo pelo Catarse em 2014. A publicação é uma compilação da sua produção entre os anos de 2012 e 2014 e já conta com uma segunda edição feita em 2016, pela editora Lote 42 . A série lhe rendeu grande visibilidade, tendo recebido prêmios, indicações em festivais e concursos de quadrinhos, ${ }^{8}$ possibilitando que seu trabalho fosse veiculado em revistas, jornais e campanhas publicitárias de grande circulação nacional; tanto que a página do Facebook Magra de ruim já conta com mais de 200.0000 seguidores. Além de fazer quadrinhos, Sirlanney, participa de rodas de discussão sobre feminismo e quadrinhos, ministra oficinas e cursos de quadrinhos e fanzines por todo o país. Lançou recentemente uma campanha pelo Apoia-se, uma plataforma de financiamento coletivo que funciona com a arrecadação de contribuições de quantias variadas destinadas ao custeio das despesas da artista.

Sirlanney nasceu em Morada Nova, cidade do interior do Ceará, em 1984, e publica seus textos e desenhos na internet, em zines e revistas há mais de 15 anos. Magra de ruim surgiu inicialmente enquanto personagem/alter ego para os contos que publicava em seu blog pessoal em 2011. Sendo que a autora só viria a construir narrativas gráficas a partir dessa personagem em 2012, segundo a mesma em

8 Em 2016, Sirlanney ganhou o prêmio Dente de ouro de melhor quadrinho, da Feira Dente Brasília, DF. Em 2015, foi finalista do prêmio HQ Mix, na categoria Publicação Independente de Autor. Ainda em 2015, venceu o prêmio Al Rio de quadrinhos na categoria Revelação na GeekExpo 2015, em Fortaleza. (Fonte: site da autora: http://www.sirlanney.com). 
entrevista ao Canal Curta!, após o contato com outras narrativas gráficas de caráter biográfico ${ }^{9}$ de outras autoras, como Persepólis ${ }^{10}$ de Marjane Satrapi.

Os quadrinhos de Sirlanney possuem diversas técnicas e formatos, passando da ilustração às tiras e narrativas curtas ou longas em sequência. ${ }^{11}$ Transitando entre a aquarela, colorização digital ou $p \& b$. Ao longo do volume é possível notar a profissionalização do traço e técnicas utilizadas pela artista ao longo dos trabalhos compilados no livro, que oferecem um panorama do início da sua investida no campo das narrativas gráficas até o ano de 2014. O livro inclui também seu primeiro zine autopublicado, o $S d d S$, que foi produzido em 2013, com a temática escolhida pelos leitores que já acompanhavam sua página, Magra de ruim, na internet.

Muito inspirada pela literatura beat, ${ }^{12}$ segundo a própria autora, a narrativa desenvolvida ao longo da publicação se volta a pensar principalmente o cotidiano e os movimentos interiores da personagem. De modo que conseguimos encontrar uma série de pistas sobre a influência dessa literatura para a construção de suas narrativas gráficas, como a narrativa do cotidiano, a experiência com drogas e a temática do exercício da sexualidade, além do sentimento de inadequação e a crítica social e aos padrões, que foi se fazendo mais presente em sua produção após a publicação do volume impresso.

\section{Eu, os outros: reinvenções e a ficcionalização de si}

O nome da personagem/alter ego da artista faz referência a forma como a autora era chamada na infância e adolescência, "magra de ruim" é uma expressão de sentido pejorativo que se refere a um corpo feminino considerado abaixo do peso padrão. É interessante perceber o jogo que a autora empreende ao se utilizar da mesma expressão enquanto estratégia para neutralizar a sua conotação negativa, já que nas narrativas não há nenhuma menção ou indicativo de uma

9 O gênero autobiográfico nos quadrinhos, segundo a crítica, surge na década de 1970 a partir de publicações underground, como as de Robert Crumb, Harvey Pekar, Justin Green, Art Spilgeman, entre outros. Sendo este um dos gêneros de produção que mais crescem nos últimos tempos, chegando inclusive a leitores que comumente não leem quadrinhos (SouzA, 2014, p.14).

10 Escrita e desenhada por Marjane Satrapi, Persépolis é uma história em quadrinhos autobiográfica que se volta para as memórias de sua infância e adolescência em meio a revolução islâmica de 1979 e o governo xiita que se estabeleceu no Irã e seus desdobramentos. Em 2007, foi adaptada em formato de animação com título homônimo.

11 A tira geralmente é definida como um texto curto, formado de um ou mais quadros, em que os personagens podem ser fixos ou não e comumente apresenta um desfecho narrativo no último quadro. A definição de quadrinho pode ser simplificada aqui, como já mencionamos, enquanto narrativa gráfica.

12 O termo beat generation teria surgido no final da década de 1940 e se refere a uma literatura que dava conta de refletir principalmente sobre as experiências subjetivas. Os beats inauguraram e reelaboraram novas modalidades de escrita, como o fluxo de pensamento, realizando inovações tanto na prosa quanto na poética, onde os poemas desenhavam outras manchas gráficas, sem rimas ou cortes convencionais, mas se voltavam também a tecer críticas a sociedade conservadora estabelecida nos Estados Unidos na década de 1950. Alguns dos autores dessa geração são: Jack Kerouack, Alen Ginsberg e Diane di Prima, dentre outros. 
sensação que aponte para a inadequação ou desconforto ocasionado pela aparência da personagem/autora.

Mesclando diversas técnicas, estilos e linguagens, a narrativa gráfica tecida por Sirlanney transita sobre várias questões como a própria produção artística, reconhecimento profissional, família, solidão, ansiedade, sexualidade, gênero e feminismo. Aqui procuraremos analisar como a autora explora em suas ilustrações a ficcionalização de si, bem como as questões de gênero e sexualidade.

Apesar de destoar de algumas das conceituações sobre o gênero autobiográfico, ${ }^{13}$ podemos caracterizar a publicação enquanto autobiográfica, pois a mesma se volta para a representação de experiências da autora e, mais raramente, as que chegam até a mesma através dos relatos das pessoas em seu entorno. Nesse sentido, encontramos os aspectos de autorreferencialidade através da construção imagética da personagem e da construção da narrativa em primeira pessoa, além dos depoimentos e entrevistas da própria autora.

Ao longo da publicação a autora elabora um interessante jogo intertextual onde suas referências literárias e das artes plásticas são reelaboradas em meio às suas narrativas autobiográficas. São extremante bem articulados os diálogos e as imagens evocadas a partir da inserção e releitura de outros personagens como Valentina, ${ }^{14}$ assim como trechos de William Shakespeare, Platão, Henri Miller, Charles Bukowski, Emily Dickinson ou Patti Smith, dentre outros.

Sua inscrição no campo da autorrepresentação pode ser entendido também como uma possibilidade de ressignificação de suas experiências e leituras. As ilustrações constantemente representam o corpo feminino e sua nudez, mas a artista retrata uma nudez que se esquiva da objetificação e erotização do corpo nu feminino há muito já escrutinado e representado pelo olhar masculino. Esse outro lugar que ocupa a representação do corpo em Magra de ruim reflete uma posição política há muito em pauta em meio aos movimentos feministas.

Durante séculos, esse corpo foi tema de discursos masculinos, objeto dos mais variados saberes, lugar de uma fala abundante, relegando a voz feminina ao silêncio. Hoje, as mulheres apropriaram-se dele, lutando pelo conhecimento e pela autonomia de seu corpo, grande bandeira do feminismo contemporâneo (XAVIER, 2008, p. 22).

Estes discursos povoam o imaginário social ao menos desde o século XVIII, e permeiam ainda hoje as ideias relacionadas a construção do gênero feminino no ocidente e por consequência estabelecem mecanismos que visam regular a sexu-

\footnotetext{
${ }^{13}$ Nos referimos em especial à construção do conceito de pacto autobiográfico como o estabeleceu Philippe Lejeune (2008).

${ }^{14}$ É uma personagem icônica dos quadrinhos, desenhada pelo italiano Guido Crepax entre os anos 1960 à 1990. Suas histórias abordam ficção científica e a dimensão erótica. A personagem é caracterizada como uma fotógrafa que entre cliques e aventuras, mergulha em um universo onírico surreal, permeado também pela temática sexual, como o BDSM.
} 
alidade através do controle do corpo das mulheres (Foucault, 2014 p.113). Entretanto, ao menos desde a década de 1970, os movimentos feministas têm se voltado para expor e pensar o funcionamento desses discursos, bem como batalhado pela autonomia e agência do seu corpo e do exercício da sexualidade. De maneira semelhante, boa parte das narrativas presentes na publicação Magra de ruim se voltam para a representação do exercício da sexualidade e do prazer, partindo da ótica do seu lugar enquanto mulher e sujeito ativo do desejo, ao passo que, revisita, e em boa medida rompe, com as construções que ligam o desejo à ideia do amor romântico e a do sexo a dimensão do interdito e da procriação, como podemos analisar na figura abaixo:

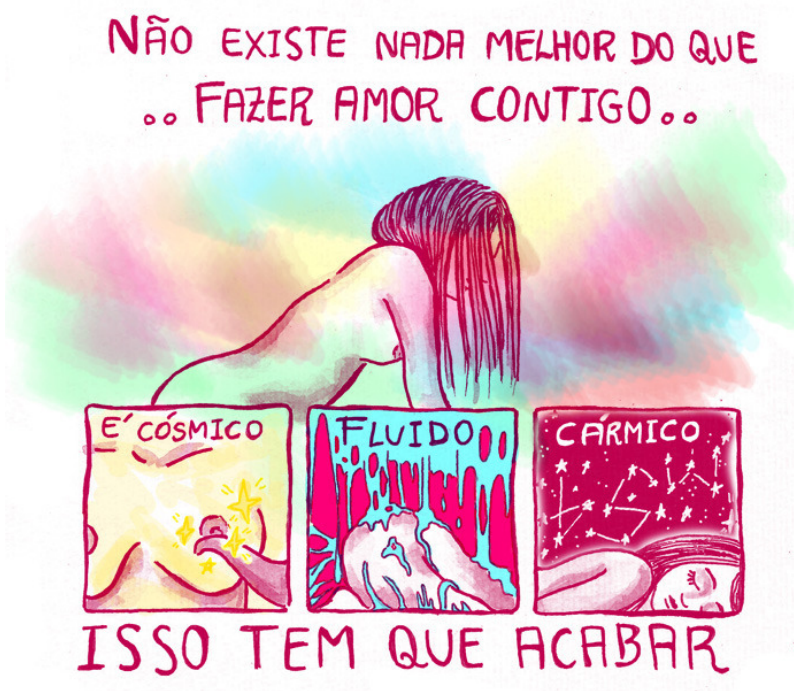

FigurA - 1, 2014, p. 137.

Há assim um investimento que se desdobra na tentativa de se pensar a sexualidade centrada no prazer, bem como levar a sexualidade feminina para além do agenciamento dos constructos relacionados ao gênero e sua dinâmica em nossa sociedade patriarcal. Dessa forma, as narrativas caminham no sentido em que pensa Butler,

A sexualidade que emerge na matriz das relações de poder não é uma simples duplicação ou cópia da lei ela mesma, uma repetição uniforme de uma economia masculinista da identidade. As produções se desviam de seus propósitos originais e mobilizam inadvertidamente possibilidades de "sujeitos" que não apenas ultrapassam os limites da inteligibilidade cultural como efetivamente expandem as fronteiras do que é de fato culturalmente inteligível (BUTLER, 2015, p. 54).

Sendo o desejo constantemente figurado e naturalizado nas narrativas, ele ocupa um outro plano do que comumente tem sido retratado nas histórias em 
quadrinhos. Na sequência abaixo é interessante notar que a personagem faz referência a figura d@outr@ através da percepção do sentimento de saudade, sendo que o desejo se manifesta assim a uma/um destinatária/o ausente, mas que em sua ausência, não impede a realização do prazer.

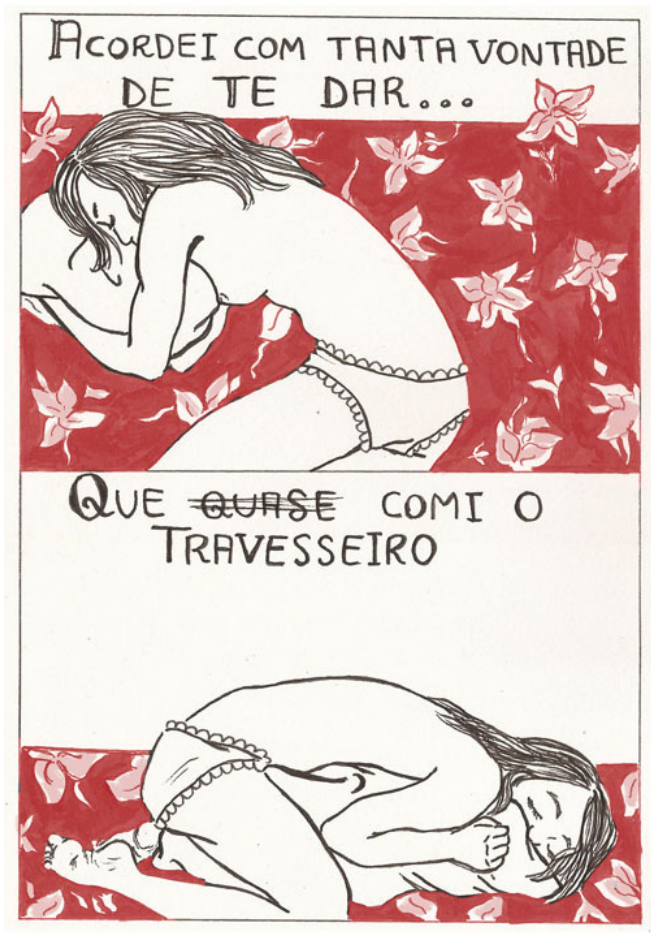

FIGURA - 2, 2013, p. 112.

Nessa sequência narrativa é interessante notar o jogo que a autora faz entre os termos "dar" e "comi". O "dar" remete a uma ideia de passividade que tradicionalmente foi associada a performatividade sexual das mulheres, mas a subversão se dá, no segundo e último quadro, quando a personagem muda a voz ou a direcionalidade da ação para si, ou seja "comi" um termo que alude a ideia de atividade, e por conseguinte a penetração, que justaposto ao corpo/voz feminina desordena o binômio passivo/ativo e mais uma vez investe na posição de autonomia e agência da personagem com relação a sua sexualidade. Sobre a questão do desejo a autora ainda produz, em outras sequências narrativas, um discurso que tensiona a hipocrisia da sociedade com relação ao exercício da sexualidade, refletindo sobre a dicotomia público/privado, em meio à reflexão sobre falácia e hipocrisia morais.

As personagens masculinas presentes na publicação tanto provocam e despertam o erótico, como também representam de certa maneira a manutenção ou o chamado a uma ordem que se inscreve através do universo das interdições sobre o comportamento e escolhas da personagem. Sendo a família, e mais especifica- 
mente a figura paterna, uma das personagens que representam esse apelo à normatização da conduta da personagem:

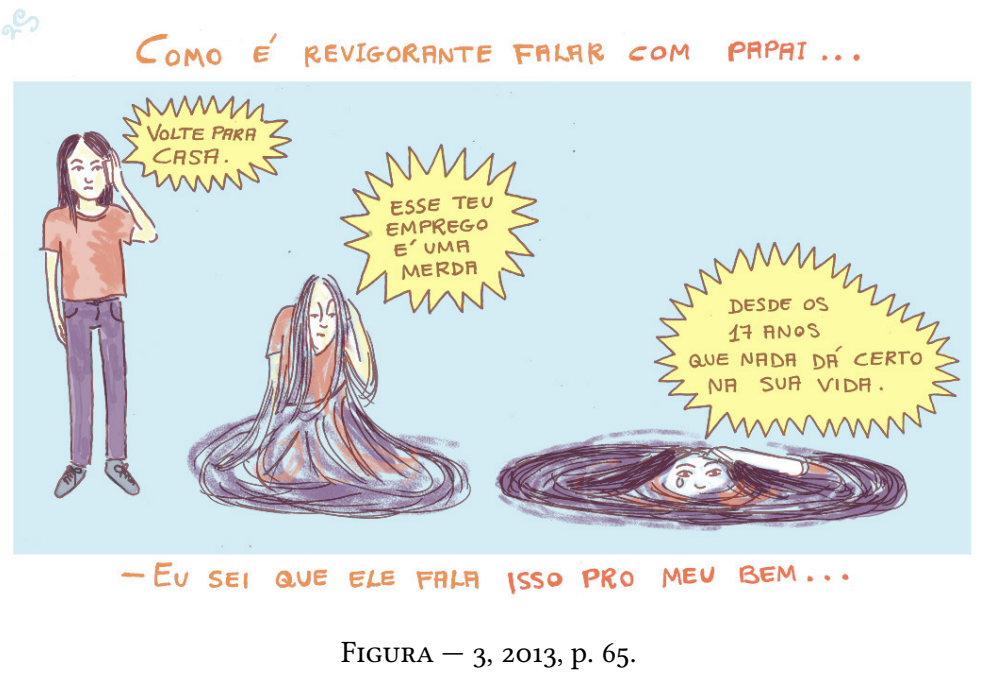

A insegurança, temor em meio a escolha profissional, assim como a questão da profissionalização também são representadas nos quadrinhos. Na tira que segue há uma evocação dos constructos pelos quais os comportamentos transgressores das mulheres têm sido historicamente enquadrados. A ideia de ser/viver enquanto artista é assombrada pelos fantasmas da loucura e da mendicância, pela falta de reconhecimento, como há muito tem acontecido na história da arte, vide biografias de Camile Claudel e Emily Dickinson, e outras/os artistas citadas/os em meio às narrativas.

Em entrevista, a autora afirmou que essas reflexões e a própria questão de se pensar enquanto mulher e artista, produtora de narrativas gráficas de caráter autobiográfico, bem como refletir sobre as temáticas relacionadas as ideias de gênero e ao feminismo só foi se dando com o transcorrer do tempo. Nós pudemos notar também que as narrativas de caráter mais abertamente feminista começam a serem mais presentes a partir das publicações relacionadas ao ano de 2014, como a FigURA - 4 .

Dentre elas, escolhemos a FigurA - 5 por a considerarmos uma das mais emblemáticas no que se refere a visibilidade dada pela artista em torno das reflexões sobre gênero e feminismo. Nesta narrativa, a autora não só reflete sobre a questão da construção da rivalidade entre mulheres e a possibilidade de desenvolver empatia e sororidade, mas também sobre a descoberta do desejo sexual por outras mulheres e de tentar representá-las em sua produção.

Nesse sentido, concluímos por ora destacando que ao longo das narrativas da Magra de ruim pudemos identificar o empreendimento de um discurso que pode ser localizado no bojo do feminismo, dialogando com muitas pautas debatidas 


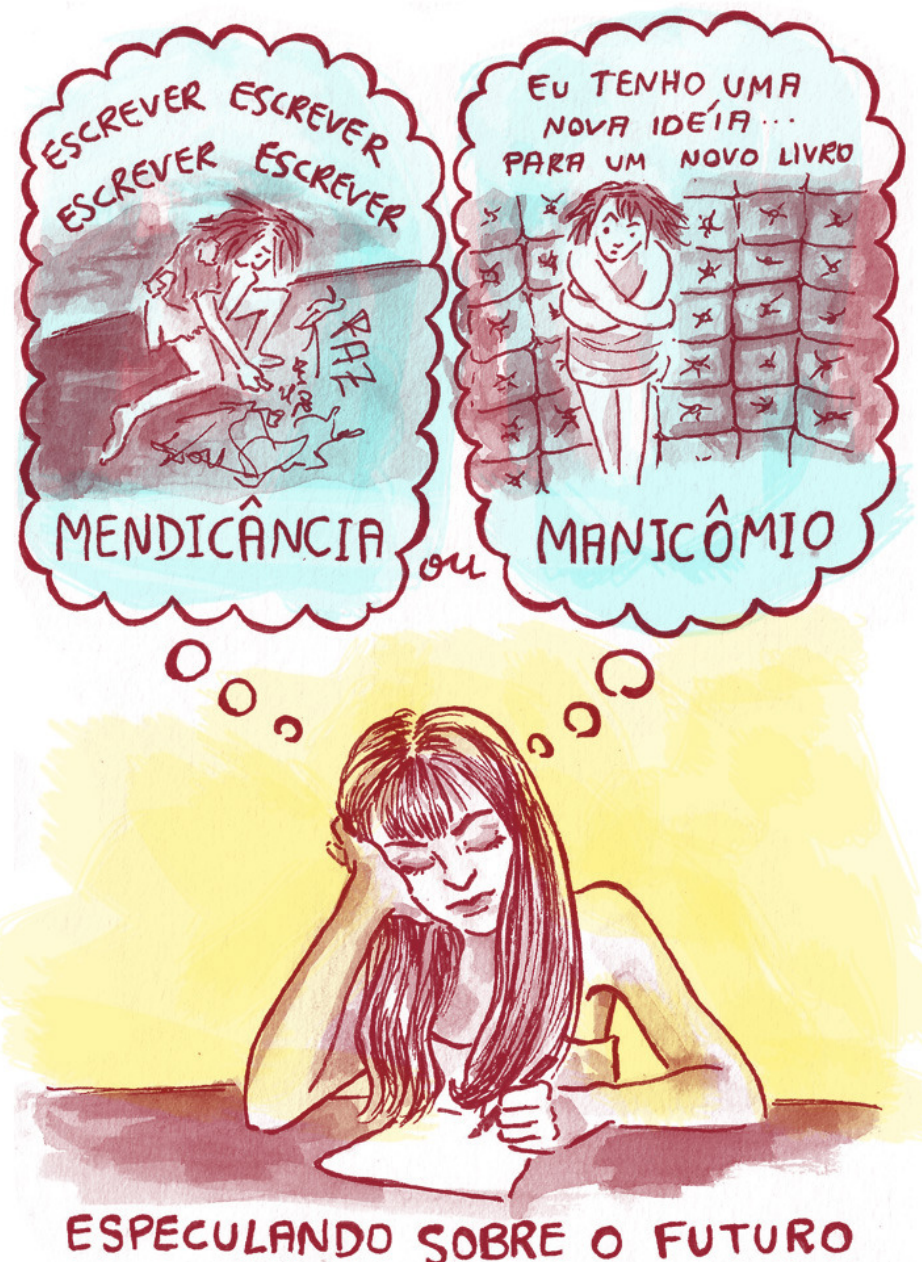

FIGURA - 4, 2014, p. 136.

pelo movimento, como a politização das dimensões associadas tradicionalmente ao âmbito do privado e individual, como as que se referem ao desejo, exercício da sexualidade, autonomia e agência sobre o próprio corpo. Além de fissurar muitos dos constructos sociais pelos quais se tenta apreender as vivências femininas, as narrativas presentes na publicação, apontam para as constantes reelaborações de si, a partir de uma in-scrita de traços e relatos biográficos. 


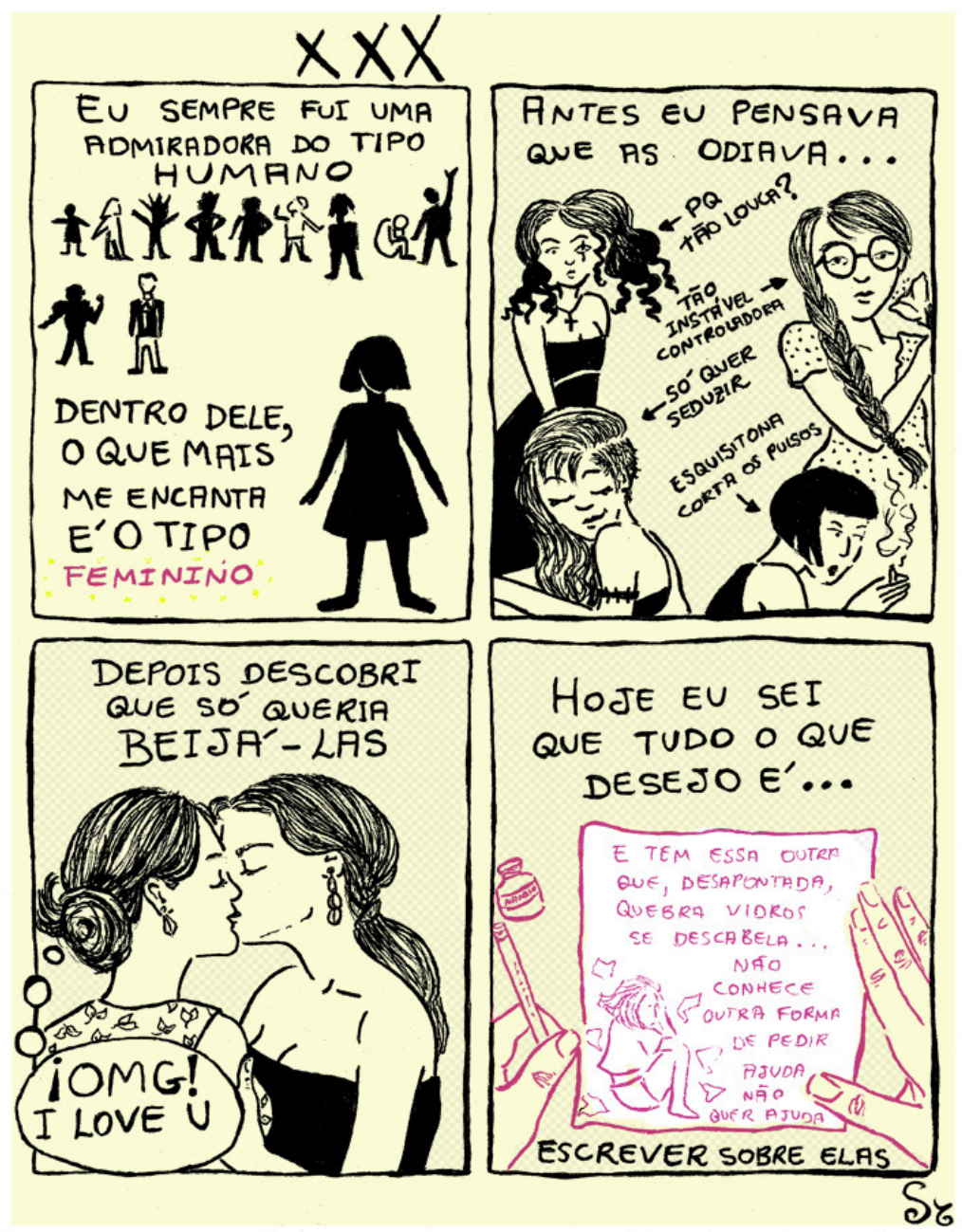

FIGURA -5 , 2014, p. 31.

\section{Referências}

Balda, Maria Antonia Díez. La imagen de la mujer en el cómic: Cómic feminista, cómic futurista y de cienciaficción. s/d. Disponível em: http://www.amit-es.org/ sites/default/files/pdf/publicaciones/antonia_diez_balda_2004.pdf. Acesso em: 10 dez. 2016.

Butler, Judith. Problemas de gênero: feminismo e subversão da identidade. São Paulo: Civilização Brasileira, 2015.

CAnal Curta!, Entrevista Sirlanney. Disponível em: https://youtu.be/ v6QkgekFfU8. Acesso em: 14 mai. 2015. 
D’Angelo, Helô. As mulheres e os quadrinhos. Revista Fórum Virtual, janeiro, 2016. Disponível em: http://www.revistaforum.com.br/semanal/mulheres-e-osquadrinhos/. Acesso em: 15 mar. 2017.

THE PUNK SINGER. (2013). Disponível em: https://www.youtube.com/watch?v= $\mathrm{DdTHg}_{4} \mathrm{SQNGE}$. Acesso em: 16 jan. 2017.

EISNer, Will. Quadrinhos e arte sequencial. São Paulo: Martins Fontes, 1989.

Foucault, Michel. História da sexualidade 1: a vontade de saber. São Paulo: Paz e Terra, 2014.

LeJeune, Philippe. O pacto autobiográfico: de Rousseau à internet. Belo Horizonte: Editora UFMG, 2008

Melo, Erica Isabel de. Riot Grrrl: feminismo na cultura juvenil punk. In: FAzendo GÊNero, 7., 2006, Florianópolis, Anais. Disponível em: http://www. fazendogenero.ufsc.br/7/artigos/E/Erica_Melo_Riot_o1.pdf. Acesso em: 13 nov. 2016.

Nochlin, Linda. Por que não houve grandes mulheres artistas? São Paulo: Edições Aurora, 2016.

Nogueira, Natânia. Rian: caricatura e pioneirismo feminino no Brasil. In: SimpóSio Nacional De História - ANPUH, 16., 2011, São Paulo, Anais. Disponível em: http://www.snh2011.anpuh.org/resources/anais/14/1312664266_ARQUIVO_ RIANEOPIONEIRISMOFEMININONACARICATURA.pdf. Acesso em: 20 dez. 2016.

NogueIra, Sirlanney. Magra de ruim. Rio de Janeiro: Edição da autora, 2014.

Pollock, Griselda. A modernidade e os espaços de feminilidade. In: MACEDo, A.G.; RAYNER, F. (Org.). Gênero, cultura visual e performance: antologia crítica. Vila Nova de Famalicão: Húmus, 2011.

Satrapi, Marjane. Persepólis. São Paulo: Quadrinhos da Cia, 2007.

SouzA, Jucelino Neco de. O discurso autobiográfico nos quadrinhos: uma arqueologia do eu na obra de Robert Crumb e Angeli, Tese de Doutorado em Ciências da Comunicação - Universidade de São Paulo, 2014.

XAVIER, Elódia. A representação do corpo no imaginário feminino: subalternidade e exclusão. In: Pires, Maria Isabel Edom (Org.). Formas e dilemas da representação da mulher na literatura contemporânea. Brasília: UnB, 2008.

Recebido em 30 de abril de 2019.

Aprovado em 17 de setembro de 2019. 


\section{Resumo/Abstract/Resumen}

\section{Magra de ruim: gênero, sexualidade e a ficcionalização de si}

\section{Mariana Souza Paim}

O objetivo do presente trabalho é analisar as representações de gênero e sexualidade presentes na publicação Magra de ruim de autoria de Sirlanney Nogueira, editada em formato impresso em 2014. O volume reúne boa parte de sua obra enquanto roteirista/ilustradora que fora publicada inicialmente em meio virtual e em diferentes zines entre os anos de 2012 e 2014. Magra de ruim foge a classificações mais sistemáticas a partir das quais se convencionou agrupar as narrativas gráficas, e lança mão através de diferentes técnicas e procedimentos, de uma narrativa que perpassa em múltiplas questões, como aquelas em torno do corpo, desejo, prazer, solidão, família, autonomia feminina e dos relacionamentos afetivos/sexuais. Nessas narrativas podemos ainda destacar o empreendimento de um discurso que pode ser localizado no bojo do feminismo e que, além de fissurar muitos dos constructos sociais pelos quais se tenta apreender as vivências femininas, aponta para as constantes reelaborações de si, a partir de uma in-scrita de traços e relatos biográficos.

Palavras-chave: narrativas gráficas, autobiografia, gênero, sexualidade, feminismo.

\section{Magra de ruim: Gender, sexuality and the fictionalization of self}

\section{Mariana Souza Paim}

This study aims to analyse the representations of gender and sexuality present in the publication Magra de ruim by Sirlanney Nogueira, published in print format in 2014. The volume gathers a good part of her work as a screenwriter/illustrator which had initially been published online and in different 'zines between 2012 and 2014. Magra de ruim escapes the more systematic classifications by which graphic narratives are usually grouped; it uses a variety of techniques and procedures, with a narrative that runs through multiple issues, such as those concerning the body, desire, pleasure, solitude, family, female autonomy and affectionate / sexual relationships. In these narratives we can also highlight the development of a discourse that can be located at the heart of feminism and that, besides breaking many of the social constructs which try to arrest feminine experiences, points to the constant re-elaborations of self, through an in-scrita of biographical accounts and stories.

Keywords: Graphical narratives, autobiography, gender, sexuality, feminism.

Magra de ruim: género, sexualidad y autoficción

\section{Mariana Souza Paim}


El objetivo de éste artículo es analizar las representaciones de género y sexualidad presentes en la publicación Magra de ruim, de la autoría de Sirlanney Nogueira y editada en forma impresa en 2014. El volumen reúne una gran parte de su trabajo como guionista e ilustradora publicado inicialmente en línea y en diferentes zines entre 2012 y 2014. Magra de ruim se escapa a aquellas clasificaciones sistemáticas en las que se solía agrupar las narrativas gráficas y utiliza distintas técnicas y procedimientos para crear una narrativa que es atravesada por múltiples cuestiones, como el cuerpo, el deseo, el placer, la soledad, la familia, la autonomía femenina o las relaciones afectivo-sexuales. En éstas narrativas podemos incluso resaltar la elaboración de un discurso que puede ubicarse como parte del feminismo y que además de romper con muchas de las construcciones sociales por las cuales se trata de aprehender la experiencia femenina, señala las constantes reelaboraciones de sí misma, desde una in-scrita de trazos y relatos biográficos.

Palabras clave: Narrativas Gráficas, Autobiografía, Género, Sexualidad, Feminismo. 